\title{
Seçilmiş Makroekonomik Göstergelerin Döviz Kuru Üzerinde Etkisi: Türkiye Ekonomisi Üzerine Bir Uygulama
}

Kemal Aka*

Öz

Döviz kuru ülkenin serbest ticaret ekonomisinde hayati bir role sahip olmakla birlikte, faiz oranı, enflasyon, cari açık, dış ticaret dengesi, işsizlik oranı vb. gibi makroekonomik ve finansal değişkenler üzerinde etki oluşturmaktadır. Döviz kurunda görülen istikrarsızlık ve ani artışlar ekonomik faaliyetlerin olumsuz seyrine yol açarak ekonomik istikrarsızlığa yol açmaktadır. Bu sebeple döviz kuru son yıllarda Türkiye ekonomisi için üzerinde çok konuşulan konuların başında gelmektedir. Bu durum da döviz kurunun stabilize edilmesi için etkili olan göstergeler ve bunlar arasındaki nedensellik ilişkisinin incelenmesini önemli kılmaktadır.Bu kapsamda çalışmada Türkiye ekonomisinden 1988Q1-2019Q2 dönemini kapsayan üç aylık veriler kullanılarak, döviz kurları ile seçilmiş makroekonomik göstergeler arasındaki etkileşim Granger nedensellik testi ile incelenmiştir.Çalışmanın sonucunda döviz kurundan cari işlemler dengesine, dış ticaret haddine ve dış ticaret dengesine doğru tek yönlü; döviz kuru ile petrol fiyatları arasında ise çift yönlü nedensellik ilişkisi bulunmuştur.

Anahtar Kelimeler: Döviz kuru, Makroekonomik göstergeler, Nedensellik testi.

JEL SInıflandırması: C10, F31, F40.

\section{Abstract - The Effect of Selected Macroeconomic Indicators on Foreign Exchange Rate: An Application on Turkey's Economy}

The exchange rate plays a vital role in the country's free trade economy and affects macroeconomic and financial variables such as interest rate, inflation rate, current account balance, foreign trade balance and unemployment rate. Instability and sudden increases in the exchange rate lead to the negative course of economic activities, leading to economic instability. For this reason, the exchange rate in recent years is one of the most talked about topics on for Turkey's economy. It is important to examine the indicators that are effective for stabilizing the exchange rate and the causality relationship between these indicators. In this study, using quarterly data covering the period from 1988Q1-2019Q2 in Turkey's economy, interaction between the exchange rate and selected macroeconomic indicators were analyzed using Granger causality test. As a result of the study, one-way from exchange rate to current account balance, terms of trade and foreign trade balance; a bilateral causality relationship between the exchange rate and oil prices was found.

Keywords: Exchange rate, Macroeconomic indicators, Causality test.

JEL Classification: C10, F31, F40.

* Marmara Üniversitesi, Bankacılık ve Sigortacıllk Yüksekokulu - E-posta: kemal.aka@marmara.edu.tr -
ORCID ID: https://orcid.org/0000-0001-6290-1451
Makale Gönderim: 14.01.2020 Makale Kabul:23.02.2020 DOI: http://dx.doi.org/10.46520/bddkdergisi.789965 


\section{Giriş}

İki ülke arasında gerçekleştirilen ödeme aracına döviz, iki ülke para biriminin birbirine değişim oranına ise döviz kuru denilmektedir. Döviz kuru, mal ve hizmetler için uluslararası ticareti ve ülkeler arasında fon transferini kolaylaştırmayı ve aynı zamanda mal fiyatlarının farklı olarak karşılaştııımasını sağlamaktadır(Abdoh vd., 2016).

Döviz kurları, dünya piyasalarındaki ekonomik faaliyetleri etkileyen en önemli göstergelerin başında gelmektedir. Bir ülkenin para biriminin istikrarsız seyri, hem ilgili ülkede hem deilgili ülkenin para birimi ile iş yapan diğer ülkelerde ekonomik faaliyetlerin olumsuz seyrine yol açarak ekonomik istikrarsızlığa yol açmaktadır.

Döviz kuru, hanehalkı, firma ve uluslararası ödemeleri yapmak için döviz alıp satan iktisadi birimlerin döviz talep ve arzına göre belirlenmektedir. Optimum döviz kuru değeri ülkelerin özellikle uluslararası ticarette rekabet edebilirliğini belirlemesi açısından oldukça önemlidir.

Döviz kuru ülke ekonomilerinin genel performansını yansıtmaktadır. Faiz oranı, enflasyon oranı, ödemeler dengesi, vergi oranı vb. gibi makroekonomik değişkenler hem döviz kurunu etkilemekte hem de döviz kuru tarafından etkilenmektedir(Abdoh vd., 2016). Döviz kuru dalgalanması, döviz kurundaki öngörülemeyen hareketlerle ilişkili risk olarak tanımlanmaktadır. Döviz kuru dalgalanmalarının ülkelerin ithalat ve ihracat davranışları üzerinde önemli bir etkisi bulunmaktadır. Ayrıca giderek artan bir şekilde gelen ve giden doğrudan yabancı yatııımlar büyük miktarda sermaye akışı yaratmakta ve döviz kurunu doğrudan etkilemektedir(Arize vd., 2000). Döviz kuru sadece ithalat, ihracat ve doğrudan yatıımları değil aynı zamanda bankacılık, sigorta, eğitim, turizm gibi çeşitli hizmet sektörlerini de etkilemektedir.

Döviz kurları, ticaret dengesi ile sermaye dengesinin korunmasına yardımcı olan serbest piyasa sisteminde uluslararası ticareti etkilemekte ve uluslarararası ticaretin dinamiklerinden etkilenmektedir. Döviz kuru, ülkelerin ithalat ve ihracat seviyesini belirlediği için çok önemlidir. Bir yerel para biriminin yabancı para cinsinden değer kazanması durumunda, ithal edilen ürünler yerel pazarda daha ucuz olacak ve yerel şirketler yabancı rakiplerinin mallarının müşteriler için daha cazip hale geleceğini göreceklerdir. Ülke güçlü bir para birimine sahipse, uluslararası piyasada malları daha pahalı hale gelir ve bu da rekabet gücünün kaybolmasına neden olur(Urrutia, vd., 2015).

Döviz kuru hareketlerini uluslararası ölçekte çerçeveleyen Bretton Woods Sistemi, ikinci dünya savaşının sonundan itibaren geçerli durumda iken, 1970'lerin başın- 
dan beri dünya döviz piyasalarındaki geçerliliğini yitirmiştir. Ulusal para birimlerinin 1970'li yıllardan sonraki dönemlerde ABD dolarına karşı oynaklığından sonra döviz kurlarındaki oynaklıklar artmış ve döviz piyasalarında belirsizlik hâkim olmuştur. Bu durum ulusal para biriminin gelecekteki değerinin tahmin edilmesini zorlaştırmıştır. Bu süreç döviz kuru belirleme konusundaki akademik ve politik tartışmaları artırmıştır. Bu süreçte döviz kurlarının belirlenmesi, tercih edilecek olan döviz kuru sistemi, döviz kurlarındaki değişimin açıklanması ve tahmini, döviz krizleri vb. kavram ve konuların önemini arttırmıştır(Heller, 1978).

Döviz kurunda yaşanabilecek ani yükseliş ve düşüşler hem hanehalkının hem de ekonominin genelinin üzerinde belirsizlik ve endişeye sebebiyet vermektedir. Döviz kurlarında meydana gelebilecek ani artışlar üretimde kullanılan ithal ara mallarının fiyatlarının artmasına ve üretilen malların daha maliyetli olmasına sebebiyet vermektedir. Bu durum da yurtiçi üreticilerin uluslararası arası rekabet düzeyini azaltmaktadır. Diğer taraftan döviz kurunun artması ile yurtiçinde üretilen ürünlerin yurtdışında yaşayanlara göre ucuzlamasına ve yurtdışındaki ürünlerinde yurtiçinde yaşayanlara göre pahalı hale geleceğinden dolayı ihracat artarken, ithalat azalacaktır. Bu durumun da cari işlemler dengesi üzerine olumlu etkisi olacaktır.

Dolayısıyla döviz kurunda yaşanan ani gelişmeler diğer makroekonomik göstergeleri de etkileyerek, ekonominin gidişatını değiştirmektedir. Bu sebeple ülkelerin merkez bankaları para politikası araçları ve farklı metotlar vasıtasıyla döviz kurlarına müdahale ederek piyasayı dengede tutmayı amaçlamaktadırlar. Dönem dönem Türkiye ekonomisinde farklı döviz kuru politikaları uygulanmış ve uygulanan döviz kuru politikaları ile ekonomi önemli ölçüde etkilenmiştir. 1980'li yıllarda Türkiye ekonomisinin liberal ekonomiye geçiş sürecinin başlamasıyla birlikte uygulanan sabit kur sistemi, sık sık devalüasyonların yaşanmasına sebep olmuştur. 1990'lı yıllara gelindiğinde ise sabit kur sisteminden vazgeçilerek serbest kur sistemine geçen Türkiye'de, 2000-2001 döneminde sabit kur sistemi uygulanmıştır.

Türkiye ekonomisinde 1994, 2000 ve 2001 yıllarında yaşanan krizler neticesinde yaşanan devalüasyonlar döviz kurlarını büyük oranda artmıştır. Türkiye, 2001 krizi ile dalgalı kur sistemine geçmiş ve döviz kurları serbest piyasada talep ve arz dengesine göre belirlenmiştir. Ekonomi yetkilileri bazı durumlarda para politikası araçlarını kullanıp, çeşitli müdahalelerde bulunarak döviz kurlarında yaşanan aşırı dalgalanmaların önüne geçmeye çalışmıştır. 2001 yılından sonraki dönemde döviz kurları incelendiğinde 2002-2013 döneminde döviz kurunun 1,30-1,91 bandında istikrarlı bir şekilde seyrettiği görülmektedir. 2013 yılından itibaren gerek ülkemizde yaşanan gelişmeler

K. Aka, "Seçilmiş Makroekonomik Göstergelerin Döviz Kuru Üzerinde Etkisi: Türkiye Ekonomisi Üzerine Bir Uygulama”, BDDK Bankacllık ve Finansal Piyasalar Dergisi, 14, (1), 2020, 99-117 
gerekse de çevre ülkelerimizde yaşanan jeopolitik risklerin ülkemizin ekonomisine de olumsuz etki yarattığı ve döviz kurunu olumsuz etkilediği söylenebilmektedir. Bununla birlikte 2016 yılında ABD'de yaşanan başkanlık seçimi sonucu başkan seçilen Trump'un Türkiye'ye karşı söylemleri ve yaptırımları neticesinde döviz kurlarında aşırı dalgalanmaların olduğu görülmektedir. Özellikle de 2018 yılı Ağustos ayında yaşanan döviz kuru artışı ile ABD Doları Türk Lirası karşısında tarihin en yüksek değerine ulaşmıştır.

Tablo 1: 1990-2019 Dönemi Döviz Kuru (ABD Doları /TL) Değerleri

\begin{tabular}{|l|l|l|l|l|l|}
\hline 1990 & 0.003 & 2000 & 0.63 & 2010 & 1,51 \\
\hline 1991 & 0.004 & 2001 & 1.23 & 2011 & 1,68 \\
\hline 1992 & 0.01 & 2002 & 1.51 & 2012 & 1,80 \\
\hline 1993 & 0.01 & 2003 & 1.50 & 2013 & 1,91 \\
\hline 1994 & 0.03 & 2004 & 1.43 & 2014 & 2,19 \\
\hline 1995 & 0.05 & 2005 & 1,35 & 2015 & 2,72 \\
\hline 1996 & 0.08 & 2006 & 1,44 & 2016 & 3,03 \\
\hline 1997 & 0.15 & 2007 & 1,31 & 2017 & 3,65 \\
\hline 1998 & 0.26 & 2008 & 1,30 & 2018 & 4,82 \\
\hline 1999 & 0.42 & 2009 & 1,55 & 2019 & 5,68 \\
\hline
\end{tabular}

Kaynak: TCMB

Yıllar itibariyle incelendiğinde döviz kur değerlerinde zaman zaman ani artışların olduğu ve bu noktada da TCMB'nin para politikası araçlarını kullanarak piyasalara müdahale ettiği görülmektedir. Merkez Bankası, politika faizlerinde değişikliğe giderek, açık piyasa işlemleri yaparak, zorunlu karşılık oranlarını ve reeskont oranlarının değiştirerek piyasaya müdahale etmektedir. Merkez bankası söz konusu müdahale yöntemleriyle döviz kurunda yaşanacak ani yükselişleri ve azalışları engellemeye çalışmaktadır(Arıcan ve Yücememiş, 2015). Şunu da özellikle belirtmek gerekir ki; anlık yapılan müdahaleler ile döviz kurlarının orta ve uzun dönemde istikrarlı kalmasında başarı sağlanması beklenemez. Dolayısıyla döviz kuruna yerinde ve etkin müdahale edilebilmesi için öncelikle döviz kuru üzerinde etkili olan faktörlerin neler olduğunun bilinmesi gerekmektedir.

Türkiye ekonomisinde 2018 yılı Ağustos ayından itibaren döviz kurlarında yaşanan ani artışların ve dolayısıyla döviz kuru artışının faiz oranı, ihracat, ithalat, enflasyon, işsizlik ve ekonomik büyüme gibi makroekonomik göstergeler üzerine etkisi, hangi 
göstergelerin döviz kuru üzerinde etkisi olduğunun anlaşılmasını önemli kılmaktadır. Çalışma Türkiye ekonomisinde döviz kurunun üzerinde etkisi olan makro ve finansal göstergelerin belirlenmesi amacını taşımaktadır. Bu amaç doğrultusunda literatürde daha önce yapılmış çalışmalar incelenerek, döviz kuru üzerinde etkili olan faktörler tespit edilmiştir. Tespit edilen değişkenlerden bazıları çalışmada modele dâhil edilmiş olup, 1988Q1-2019Q2 dönemi verilerine göre incelenmiştir.

Bu çalışma, Türkiye'de gelecekteki döviz kurları için önemli faktörlerin belirlenmesi ve tahmin edilmesi bakımındankatkı sağlamaktadır. Dolayısıyla hükümetin döviz kurunda yaşanacak değişikliklere hazırlıklı olmasına, gerçekçi ve doğru kararlar vermesine yardımcı olacaktır.Bu kapsamda çalışmada önce literatürde yapılan çalışmalar, çalışmalarda kullanılan değişkenler ve çalışmaların sonuçları incelenmiştir. Daha sonra literatürde kullanılan değişkenler kullanılarak kurulan ekonometrik model analiz edilmiştir. Son kısımda ise ekonometrik analiz sonucunda bulunan bulgular değerlendirilmiştir.

\section{Literatür Taraması}

Döviz kuru ile ilgili olarak literatürde çeşitli ülkelerde çeşitli değişkenler ile birçok çalışma yapılmıştır. Holden vd. yaptıkları çalışmada 76 ülkeden 1794-1975 yıllarına ait aylık verileri kullanarak döviz kurunun belirleyicilerini analiz etmişlerdir. Çalışmanın sonucunda döviz kuru ile enflasyon ve ekonomik kalkınma pozitif; dışa açıklık oranı ve toplam ihracat ile arasında ise negatif ilişki olduğu sonucuna ulaşılmıştır(Holden vd., 1979).

Juhn ve Mauro yaptıkları çalışmada uzun dönemde döviz kurunun belirleyicilerini incelemişlerdir. Çalışmanın sonucunda döviz kuru üzerinde ekonomik büyüklüğün önemli bir etkisinin olduğunu ortaya koymuşlardır(Juhn ve Mauro, 2002).

Şimşek, yaptığı çalışmada Türkiye özelinde 1975-2003 dönemine ait yıllık verileri kullanarak reel döviz kurunun uzun dönemli belirleyicilerini incelemiştir. Çalışmanın sonucunda uzun dönemde reel döviz kuru üzerinde net yabancı sermaye girişi, dış ticaret dengesi, ticaret haddi ve para arzının etkisi olduğu sonucuna ulaşılmıştır. Bununla birlikte uzun dönemde reel döviz kuru ile para arzı ve yabancı sermaye girişininpozitif; dış ticaret haddinin ise negatif etkisi olduğu sonucuna ulaşılmıştır(Şimşek, 2004).

Candelon vd. yaptıkları çalışmada 8 AB ülkesinden 1993-2003 dönemine ait verileri kullanarak reel döviz kurunun belirleyicilerini incelemişlerdir. Çalışmanın sonucunda reel döviz kuru ile verimlilik düzeyi arasında pozitif; dışa açıkıı oranı ile arasında ise negatif ilişki olduğu sonucuna ulaşılmıştır(Candelon vd., 2007).

K. Aka, "Seçilmiş Makroekonomik Göstergelerin Döviz Kuru Üzerinde Etkisi: Türkiye Ekonomisi Üzerine Bir Uygulama”, BDDK Bankacilık ve Finansal Piyasalar Dergisi, 14, (1), 2020, 99-117 
Gül vd. yaptıkları çalışmada Türkiye'den 1984-2006 dönemine ait aylık verileri kullanarak döviz kurları ile faiz oranları arasında ilişki olup olmadığını test etmişlerdir. Çalışmanın sonucunda döviz kurundan faiz oranlarına yönelik tek yönde ilişki olduğu sonucuna ulaşmışlardır(Gül vd., 2007).

Cayen vd. yaptıkları çalışmada Euro bölgesi, Avustralya, Kanada, Japonya, Yeni Zelanda ve İngiltere'den 1980-2007 dönemine ait panel verileri kullanarak uzun vadede döviz kurunun belirleyicileri incelemişlerdir. Çalışmanın sonucunda borç oranı ve emtia fiyatlarının döviz kuru üzerinde etkisi olduğunu ortaya koymuşlardır(Cayen vd., 2010).

Chowdhury yaptığı çalışmada Avustralya'nın 1984-2011 dönemine ait verilerini kullanarak reel döviz kurunun belirleyicilerini incelemiştir. Çalışmanın sonucunda Avustralya'da uzun dönemde dış ticaret dengesi, kamu harcamaları ve net dış borçlardaki artışların reel döviz kurunun değerini artırdığını, faiz oranları, dışa açıkıı oranı, teknolojik ve verimlilik artışının ise reel döviz kurunun değerini azalttığını göstermektedir(Chowdhury, 2012).

Saeed vd.yaptıkları çalışmada Pakistan'ın 1982-2010 dönemine ait aylık verileri kullanılarak döviz kurunun belirleyicilerini incelemişlerdir. Çalışmanın sonucunda döviz kuru üzerinde para stokunun ve borcun pozitif etkisi olduğu, siyasal istikrarsızlığının ise negatif etkisi olduğu sonucuna ulaşmışlardır(Saeed vd., 2012).

Kia, yaptığı çalışmada Kanada'da ekonomisinden 1972-2010 dönemine ait verileri kullanarak reel döviz kurunun belirleyicilerini incelemiştir. Çalışmanın sonucunda faiz oranındaki değişimin, para arzının, emtia fiyatının ve kişi başına düşen borcun artmasının kısa vadede reel döviz kurunun büyümesi üzerinde olumsuz bir etkisi olduğu sonucuna ulaşmıştır (Kia, 2013).

Mirchandani, yaptığı çalışmada Hindistan'ın1991-2010 dönemine ait yıllık verilerini kullanarak döviz kurunda değişikliklere yol açan çeşitli makroekonomik değişkenleri incelemiştir. Çalışmanın sonucunda döviz kuru ile enflasyon ve faiz oranı arasında negatif; GSYH büyüme oranı ve cari işlemler dengesi ile arasında ise pozitif bir ilişki bulunmuştur(Mirchandani, 2013).

Twarowska ve Kakol, yaptıkları çalışmada Polonya'nın2000-2013 dönemine ait yıllık verilerini kullanarak döviz kurunun belirleyicilerini incelemişlerdir. Çalışmanın sonucunda finansal işlemler dengesi, enflasyon oranının ve faiz oranının döviz kuru seviyesini belirleyen en önemli faktörler olduğunu ortaya koymuşlardır.Polonya'nın finansal işlemlerindeki ve faiz oranlarındaki artışın ülkenin para biriminin değer kazanmasına katkıda bulunurken, enflasyondaki artışın ise ülkenin para biriminin değer 
kaybetmesine sebep olduğunu ortaya koymuşlardır(Twarowska ve Kakol, 2014).

Kaplan ve Yapraklı yaptıkları çalışmada, kıılgan 12 gelişmekte olan ülkeden 20002012 dönemine ait panel verileri kullanarak döviz kurunun belirleyicilerini incelemişlerdir. Çalışmanın sonucunda döviz kuru üzerindeenflasyon oranının, cari açığın, brüt kamu borcunun ve özel sektör yurt içi kredi borcunun negatif etkisi;dış borç oranı ve döviz rezervinin ise pozitif etkisi olduğu sonucuna ulaşmışlardır(Kaplan ve Yapraklı, 2014).

Urrutia vd. yaptıkları çalışmada Filipinler'den 2004-2014 dönemine ait çeyreklik verilerini kullanarak döviz kuru üzerinde etkili olan değişkenlerin neler olduğunu analiz etmişlerdir. Çalışmada bağımsız değişken olarak, faiz oranı, enflasyon oranı, işgücüne katılma oranı, ihracat ve ithalat değişkenleri kullanılımıştır. Çalışmanın sonucunda faiz oranı ve işgücüne katılma oranının döviz kuru üzerinde etkisi olan değişkenler olduğunu ortaya koymuşlardır(Urrutia vd., 2015).

Semuel ve Nurina, yaptıkları çalışmada Endonezya'da enflasyon, faiz oranı ve döviz kurunun GSYH üzerine etkisini analiz etmişlerdir. Çalışmanın sonucunda GSYH ile döviz kuru üzerinde pozitif ilişki bulunmuştur(Semuel ve Nurina, 2015).

Ramasamy ve Abar, döviz kuru üzerine etkili olan makroekonomik değişkenlerin etkisini analiz etmişlerdir. Çalışmanın sonucunda faiz oranı, ödemeler dengesive yolsuzluk oranının döviz kuru üzerinde negatif etkisi olduğunu ortaya koymuşlardır(Ramasamy ve Abar, 2015).

Abdoh vd. yaptıkları çalışmada ASEAN ülkelerinde 2005-2014 dönemine ait yıllık panel veriler kullanılarak döviz kuru dalgalanmalarını etkileyen makroekonomik faktörleri incelemişlerdir. İncelenen makroekonomik değişkenler arasında yalnızca ihracatın döviz kuru ile önemli ilişkiler gösterdiği ortaya konulmuştur(Abdoh vd.,2016).

Monica ve Santhiyavalli, yaptıkları çalışmada Hindistan'ın 2008-2014 dönemine ait verilerini kullanarak döviz kurunun belirleyicilerini incelemişlerdir. Çalışmanın sonucunda cari işlemler dengesi, döviz rezervi ve GSYH'nin döviz kurunu etkileyen en önemli değişkenler olduğunu ortaya koymuşlardır(Monica ve Santhiyavalli, 2017).

Mariano vd. yaptıkları çalışmada Filipinler'in 1973-2014 dönemine ait yıllık verilerini kullanarak reel döviz kurunun belirleyicilerini incelemişlerdir. Çalışmanın sonucunda döviz kuru ile GSYH, net dış varlıklar ve ithalat kısıtlamalarıarasında pozitif; petrol fiyatları ile arasında ise negatif ilişki bulunmuştur. Ayrıca bütçe açığı ve para arzının döviz kuru üzerinde kısa ve uzun vadede pozitif, orta vadede ise negatif etkisi olduğunu ortaya koymuşlardır(Mariano vd., 2016).

K. Aka, "Seçilmiş Makroekonomik Göstergelerin Döviz Kuru Üzerinde Etkisi: Türkiye Ekonomisi Üzerine Bir Uygulama”, BDDK Bankacllık ve Finansal Piyasalar Dergisi, 14, (1), 2020, 99-117 
Parveen vd. yaptıkları çalışmada Pakistan'ın 1975-2010 dönemine ait yıllık verilerini kullanarak döviz kurunun değişmesinde etkili olan faktörleri analiz etmişlerdir. Çalışmanın sonucunda döviz kurunu etkileyen en önemli faktörlerin sırasıyla enflasyon, ekonomik büyüme, ihracat ve ithalat, olduğunu ortaya koymuşlardır. Bununla birlikte döviz kuru ile enflasyon, ekonomik büyüme ve ihracat ile arasında pozitif; ithalat ile arasında ise negatif ilişki bulunmuştur (Parveen, 2012).

Khan yaptığı çalışmada Pakistan'da 2006-2013 dönemine ait aylık verileri kullanarak döviz kurunun değişiminde etkili olan faktörleri analiz etmiş̧ir. Çalışmanın sonucunda döviz kurunu etkileyen en önemli faktörlerin sırasıyla \%63,3 ile enflasyon, \%41,5 ile petrol fiyatları ve \%34,5 ile reel faiz oranı olduğunu ortaya koymuştur(Khan, 2014).

Kartal vd. yaptıkları çalışmada Türkiye'nin 2006-2017 dönemine ait aylık verilerini kullanarakdöviz kurları üzerinde etkisi olan faktörleri incelemişlerdir. Çalışma sonucunda ABD Dolar üzerinde en etkili değişkenlerin para arzı, bütçe açığı, yabancı yatırımlar, işsizlik, iç borç, ithalat, enflasyon ve cari açık; Euro üzerinde en etkili değişkenlerin ise para arzı, bütçe açığı, cari açık, yabancı yatırımlar, ham petrol ithalatı ve ihracat olduğunu ortaya koymuşlardır (Kartal vd., 2018).

Şit ve Karadağ yaptıkları çalışmada Türkiye ekonomisi özelinde 2003-2018 dönemine ait aylık verileri kullanarak döviz kuru üzerinde etkili olan faktörleri incelemişlerdir. Çalışmanın sonucunda hem kısa hem de uzun dönemde döviz kuru ile cari açık, dış ticaret açığı, Merkez Bankası döviz rezervi ve TÜFE değişkenleri arasında pozitif; faiz değişkeni ile arasında ise negatif bir ilişki bulmuşlardır (Şit ve Karadağ, 2019).

\section{Veri Seti, Amaç, Yöntem ve Bulgular}

\subsection{Veri Seti}

Bu çalışmada, Türkiye'de 1998Q1 - 2019 Q2 dönemine ait çeyreklik veriler kullanılarak döviz kurları ile seçilmiş makroekonomik göstergeler arasındaki etkileşim Granger nedensellik testi kullanılarak incelenmiştir.Türkiye'de döviz olarak genellikleUSD ve Euro kullanılmaktadır. Bu çalışmada ise döviz kuru olarak ABD Doları inceleme konusu yapılmıştır. Çalışmada kullanılan veri seti TCMB'nin elektronik veri dağıtım sistemi olan EVDS sayfasındanelde edilmiş̧ir.

Çalışmada kullanılan değişkenler literatürde yapılmış çalışmalar incelenerek modele dâhil edilmiştir. Anlamlı bulunan değişkenler cari işlemler dengesi, dış ticaret haddi, dış ticaret dengesi ve petrol fiyatları değişkenleridir. Söz konusu bu değişkenlerden cari işlemler dengesi değişkeni, Mirchandani(2013), Twarowska ve K kol(2014), 
Monica ve Santhiyavalli(2017) ve Şit ve Karadağ(2019)'ın yaptıkları çalışmalardan; dış ticaret haddi değişkeni, Şimşek(2004)'in yaptığı çalışmadan; dış ticaret dengesi değişkeni, Juhn ve Mauro(2002), Şimşek(2004) ve Chowdhury(2012)'in yaptıkları çalışmalardan; petrol fiyatları değişkeni ise Khan(2014) ve Mariano vd.(2016) yaptıkları çalışmalardan esinlenerek modele dâhil edilmiştir.

Modelde yer alan değişkenler aşağıdaki Tablo 2'de gösterilmiş̧tir.

Tablo 2: Modelde Yer Alan Değişkenler

\begin{tabular}{|l|c|l|}
\hline \multicolumn{1}{|c|}{ Değişkenler } & Sembol & \multicolumn{1}{c|}{ Açıklama } \\
\hline Döviz Kuru & KUR & ABD Dolarının Türk Lirası Karşısındaki Değeri \\
\hline Dış Ticaret Haddi & DTH & inracat / İthalat \\
\hline Dış Ticaret Dengesi & DTD & İhracat - İthalat \\
\hline Petrol Fiyatları & PET & Brent Petrol Spot FOB Fiyatı \\
\hline Cari İşlemler Dengesi & CID & Cari İşlemler Hesabı \\
\hline
\end{tabular}

\subsection{Amaç ve Yöntem}

Çalı̧̧ma literatürde yapılmış çalışmalardan esinlenerek, döviz kuru üzerine etkisi olan seçilmiş makroekonomik göstergelerin, Türkiye özelinde 1998Q1 - 2019 Q2 dönemini kapsayan veriler kullanılarak döviz kuru üzerinde etkisinin ne olduğu amaçlanmaktadır.

Çalışmanın analiz kısmında döviz kuru ile diğer değişkenlerin her biri arasında nedensellikleri incelenmiştir. İki değişken arasındaki nedensellik ilişkisini test etmek amacıyla çeşitli nedensellik testleri kullanılmaktadır. Granger nedensellik testi, Sims testi, Geweke-Meese-Dent testi, Pierce-Haugh testi ve Geweke testleri genellikle kullanılan nedensellik testleridir. Çalışmada söz konusu bu testlerden Granger nedensellik testi kullanılmışıı. Granger nedensellik testinin tercih edilmesinin sebebi, hem uygulamada kolay ve basit olması hem de test sonuçlarındaki bazı çıkarımlarının olmasıdır.

\subsubsection{Granger Nedensellik Testi}

Çalışmanın analiz kısmında Granger nedensellik testi kullanılmıştır. Bu test iki değişken arasında ilişki olup olmadığını ve ilişkinin yönünü test eden en etkili testlerden biri olmasından dolayı tercih edilmiştir (Granger,1969).

K. Aka, "Seçilmiş Makroekonomik Göstergelerin Döviz Kuru Üzerinde Etkisi: Türkiye Ekonomisi Üzerine Bir Uygulama”, BDDK Bankacilık ve Finansal Piyasalar Dergisi, 14, (1), 2020, 99-117 
Testin hipotezleri ve hesaplamada kullanılan denklemler aşağıdaki gibidir(Granger, 1969).

$\mathrm{H}_{0}$ :Granger nedeni değildir.

$\mathrm{H}_{1}$ : Granger nedenidir.

$$
\begin{aligned}
& X_{t}=\sum_{j=1}^{m} a_{j} X_{t-j}+\sum_{j=1}^{m} b_{j} Y_{t-j}+\varepsilon_{t} \\
& Y_{t}=\sum_{j=1}^{m} c_{j} X_{t-j}+\sum_{j=1}^{m} d_{j} Y_{t-j}+\eta_{t}
\end{aligned}
$$

Yukarıdaki denklemlerde $a, b, c$, d gecikme katsayılarını, m gecikme uzunluğunu ve $\varepsilon_{t}$ ve $\eta_{t}$ ise hata terimlerini göstermektedir.

Granger nedensellik testi, 1 ve 2. denklemlerdeki hata terimlerinden önce yer alan bağımsız değişkenlerin gecikmeli değerlerinin katsayılarının sıfıra eşit olup olmadığını test etmektedir. Çift taraflı kurulan hipoteze göre nedensellik tek taraflı mı yoksa karşılıklı mı olduğu belirlenmektedir. 1. denklemde belirli bir anlamlılık düzeyinde $b$ değerleri sıfırdan farklı ise " $Y_{t}^{\prime}$ nin $X_{t}^{\prime}$ ye neden olduğu", başka bir ifadeyle " $Y_{t}$ ' $X_{t}^{\prime}$ nin Granger nedeni olduğu" şeklinde ifade edilmektedir. Bu durum $Y_{t}^{\prime}$ den $X_{t}^{\prime}$ ye doğru tek yönlü ilişki olduğu anlamına gelmektedir.

Diğer taraftan $c$ değerlerinin belli bir anlamlılık düzeyinde sıfırdan farklı olması durumunda ise " $X_{t}^{\prime}$ nin $Y_{t}^{\prime}$ ye neden olduğu", başka bir ifadeyle " $X_{t^{\prime}} Y_{t}^{\prime}$ nin Granger nedeni olduğu" şeklinde ifade edilmektedir. Bu durum da $X_{t}^{\prime}$ den $Y_{t}^{\prime}$ ye doğru tek yönlü ilişki olduğu anlamına gelmektedir.

Söz konusu bu iki koşul geçerli olduğu takdirde, hem $b$ hem de $c$ katsayılarının belli bir anlamlıık düzeyinin sıfırdan farklı olmaları durumunda hem $Y_{t^{\prime}} X_{t}^{\prime}$ nin hem de $X_{t^{\prime}} Y_{t}^{\prime}$ nin Granger nedeni olarak ifade edilmektedir. Burada karşılıklı, başka bir ifadeyle, çift yönlü nedensellikten bahsedilmektedir. Eğer koşullar geçerli olmadığı, b ve c katsayılarının belli bir anlamlılık düzeyinden sıfırdan farklı olmamaları durumunda ise, iki değişkenin birbirinin nedeni olmadığı, başka bir ifadeyle, $Y_{t}$ ve $X_{t}^{\prime}$ nin birbirinden bağımsız seriler olduğu anlamına gelmektedir(Granger, 1969). 


\subsection{Bulgular}

Granger nedensellik testini uygulamak için veri setinin durağan olması gerekmektedir. Çalışmanın ekonometrik analiz kısmına geçmeden önce söz konusu değişkenlerin durağanlığıtest etmek için Genişletilmiş Dickey-Fuller (ADF) birim kök testikullanulmıştır.Birim kök testi yapmadan önce çalışmanın kapsadığı dönemde yaşanan krizlerin de etkisiyle serilerde kırılganlıklarınolup olmadığı incelenmiştir (Şekil 1).

\section{Şekil 1: Serilerin Kırılganlıkları}

KUR
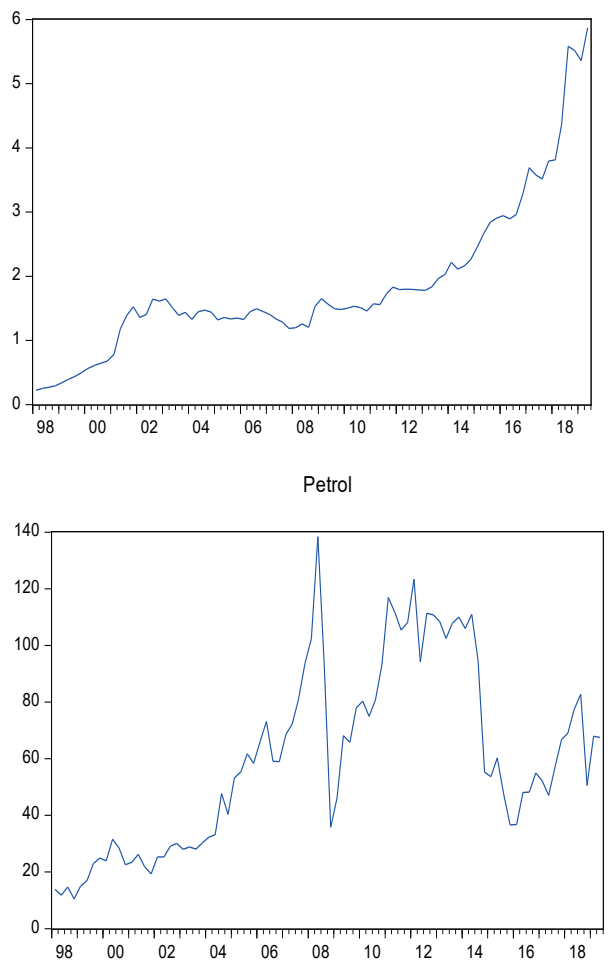

Dış Ticaret Haddi
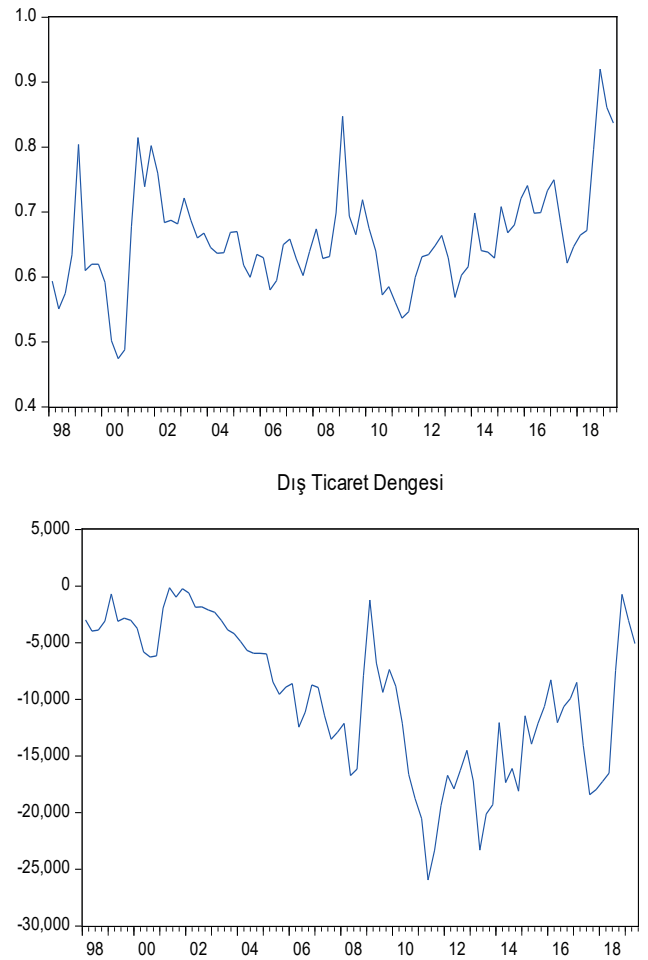

Cari İşlemler Dengesi

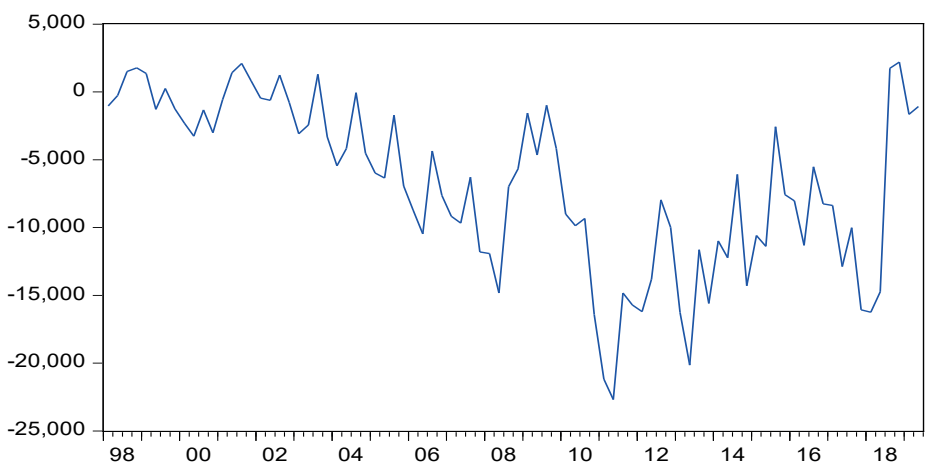

K. Aka, "Seçilmiş Makroekonomik Göstergelerin Döviz Kuru Üzerinde Etkisi: Türkiye Ekonomisi Üzerine Bir Uygulama", BDDK Bankacılık ve Finansal Piyasalar Dergisi, 14, (1), 2020, 99-117 
Şekil 1 de modelde yer alan serilerin grafikleri incelendiğinde, serilerin grafiklerinde kırılganlıkların olduğu görülmektedir. Bu sebeple burada kırılmalı birim kök testini incelemek daha yerinde olmaktadır. Kırılmalı birim kök test sonuçları aşağıdaki tabloda gösterilmiştir.

Tablo 3: Değişkenlerin ADF Birim Kök Testi Sonuçları

\begin{tabular}{|c|c|c|c|c|c|c|}
\hline \multirow{2}{*}{ Değişken } & \multirow{2}{*}{ Trend Yapısı } & \multirow{2}{*}{$\begin{array}{l}\text { ADF Test } \\
\text { İstatistiği }\end{array}$} & \multicolumn{3}{|c|}{ Kritik Değerler } & \multirow{2}{*}{ Prob. } \\
\hline & & & $1 \%$ & $5 \%$ & $10 \%$ & \\
\hline$D(K \cup R)^{*}$ & Sabit & -10.82 & -4.95 & -4.44 & -4.19 & $<0.01$ \\
\hline DTH & Sabit & -5.27 & -4.95 & -4.44 & -4.19 & $<0.01$ \\
\hline DTD & Sabit ve Trend & -5.39 & -5.07 & -4.52 & -4.26 & $<0.01$ \\
\hline PET & Sabit ve Trend & -5.67 & -5.35 & -4.86 & -4.61 & $<0.01$ \\
\hline CID & Sabit ve Trend & -6.25 & -5.72 & -5.18 & -4.89 & $<0.01$ \\
\hline
\end{tabular}

*Değişken birinci farkta durağan bulunmuş ve analizde o şekilde kullanılmıştır.

Tablo 3 incelendiğinde modelde yer alan değişkenlerden kur değişkeninin birinci dereceden diğer değişkenlerin ise düzeydedurağan olduğu başka bir ifadeyle birim kök olmadığı görülmektedir. Dolayısıyla değişkenler arasında ilişki olup olmadığını test etmek için Granger Nedensellik analizini uygulamada bir engel olmadığı görülmüştür.

Granger nedensellik testinde her değişkene ilişkin optimal gecikme uzunluğu Akaike, Schwarz ve Hannan-Quinn gibi bilgi kriterleri vasıtasıly belirlenmektedir. Bu çalışmada uygun gecikme uzunluğu Schwarz bilgi kriteri kullanılarak belirlenmiştir. Burada cimrilik prensibine göre minimum gecikme değerini veren Schwarz kriteri dikkate alınarak gecikme uzunluğu 1 olarak seçilmiştir (Gujarati, 2003). 
Tablo 4: Gecikme Uzunluğu Seçim Kriterleri

\begin{tabular}{|c|c|c|c|c|c|c|}
\hline \multicolumn{7}{|c|}{$\begin{array}{l}\text { VAR Gecikme Uzunluğu Seçim Kriterleri } \\
\text { İçsel Değişkenler: KUR, DTH, DTD, PET, CID } \\
\text { Dışsal Değiş̧kenler: C } \\
\text { Örneklem: 1998Q1 } 2019 \text { Q2 } \\
\text { Gözlem sayısı: } 81\end{array}$} \\
\hline Lag & LogL & LR & FPE & AIC & SC & HQ \\
\hline 0 & -2.501 .257 & NA & $3.10 e+19$ & 6.190 .759 & 6.208 .496 & 6.197 .875 \\
\hline 1 & -2.248 .748 & 4.613 .747 & $1.48 e+17$ & 5.656 .169 & $57.80325^{*}$ & 5.705 .982 \\
\hline 2 & -2.173 .545 & 1.262 .680 & $5.71 e+16$ & 5.559 .369 & 5.789 .946 & 5.651 .880 \\
\hline 3 & -2.124 .372 & 7.527 .635 & $4.28 e+16$ & 5.526 .845 & 5.863 .841 & 5.662 .052 \\
\hline 4 & -2.056 .396 & 93.99192* & $2.09 e+16^{*}$ & $54.47891^{*}$ & 5.891 .307 & $56.25795^{*}$ \\
\hline $\begin{array}{l}{ }^{*} . . \mathrm{kr} \\
\text { LR: A } \\
\text { FPE: } \\
\text { AIC: } \\
\text { SC: } 5 \\
\text { HQ: }\end{array}$ & $\begin{array}{l}\text { i tarafından s } \\
\text { şık değiştiriln } \\
\text { lai hata tahm } \\
\text { aike bilgi krit } \\
\text { warz bilgi krit } \\
\text { nnan-Quinn b }\end{array}$ & $\begin{array}{l}\text { n gecikme sı } \\
2 \text { test istatisti } \\
\text { iteri }\end{array}$ & $\begin{array}{l}\text { gösterir. } \\
5 \text { düzeyi) }\end{array}$ & & & \\
\hline
\end{tabular}

Schwarz bilgi kriterine göre belirlenen 1 gecikme uzunluğuna ait Granger nedensellik test sonuçları aşağıdaki Tablo 5 'te gösterilmiştir.

\section{Tablo 5: Nedensellik Testi Sonuçları}

\begin{tabular}{|c|c|c|c|}
\hline Nedensellik Yönü & Test İstatistiği & Prob. & Karar \\
\hline d(Döviz Kuru) -> Cari İşlemler Dengesi & 6.214139 & 0.0127 & $\mathrm{H}_{0}$ reddedilir. \\
\hline Cari İşlemler Dengesi ->d(Döviz Kuru) & 0.511194 & 0.4746 & $\mathrm{H}_{0}$ reddedilemez. \\
\hline d(Döviz Kuru) -> Dış Ticaret Haddi & 9.924481 & 0.0016 & $\mathrm{H}_{0}$ reddedilir. \\
\hline Dış Ticaret Haddi ->d(Döviz Kuru) & 0.284004 & 0.5941 & $\mathrm{H}_{0}$ reddedilemez. \\
\hline d(Döviz Kuru) -> Dış Ticaret Dengesi & 10.09166 & 0.0015 & $\mathrm{H}_{0}$ reddedilir. \\
\hline Dış Ticaret Dengesi ->d(Döviz Kuru) & 0.478223 & 0.4892 & $\mathrm{H}_{0}$ reddedilemez. \\
\hline d(Döviz Kuru) -> Petrol & 3.576037 & $0.0586^{*}$ & $\mathrm{H}_{0}$ reddedilemez. \\
\hline Petrol ->d(Döviz Kuru) & 5.773312 & 0.0163 & $\mathrm{H}_{0}$ reddedilir. \\
\hline
\end{tabular}

*\%10 anlam düzeyinde $\mathrm{H}_{0}$ reddedilir.

Gözlem Sayısı 84'tür.

$\mathrm{H}_{0}$ :Granger nedeni değildir. $\mathrm{H}_{1}$ : Granger nedenidir.

Tablolardaki döviz kuru değişkeninin 1. farkta durağan olması sebebiyle bu durum d harfi ile gösterilmiştir.

K. Aka, "Seçilmiş Makroekonomik Göstergelerin Döviz Kuru Üzerinde Etkisi: Türkiye Ekonomisi Üzerine Bir Uygulama”, BDDK Bankacilık ve Finansal Piyasalar Dergisi, 14, (1), 2020, 99-117 
Tablo 5 incelendiğinde döviz kuru ile cari işlemler dengesi arasındaki Granger nedensellik analiz sonuçlarına göre döviz kurunun \%5 anlamlılık düzeyinde cari işlemler dengesinin Granger nedeni olduğu fakat cari işlemler dengesinin döviz kurunun Granger nedeni olmadığı görülmektedir. Başka bir ifadeyle döviz kurundan cari işlemler dengesine doğru tek yönde ilişki bulunmuştur. Çıkan sonuç literatürde Mirchandani(2013), Monica ve Santhiyavalli(2017) ve Şit ve Karadağ(2019)'ın yaptıkları çalışmaların sonuçlarıyla benzerlik göstermiştir.

Döviz kurunun \%5 anlam düzeyinde dış ticaret haddinin Granger nedeni olduğu fakat dış ticaret haddinin döviz kurunun Granger nedeni olmadığı görülmektedir. Başka bir ifadeyle döviz kurundan dış ticaret haddine doğru tek yönde ilişki bulunmuştur. Dış ticaret haddi değişkenin hesaplama formülünden yola çıkarak ihracat/ithalat üzerinden yorum yapacak olursak, ihracat ve ithalat değerlerindeki değişimlerin döviz kuru üzerinde etkili olduğu söylenebilir. Literatür incelendiğinde Şimşek(2004) uzun dönemde dış ticaret haddinin reel döviz kuru üzerinde etkisi olduğunu, Abdoh vd.(2016) ihracatın döviz kurunun belirleyicisi olduğunu, Parveen vd.(2012) ihracat ve ithalatın döviz kurunu etkileyen en önemli faktörler olduğunu ortaya koymuşlardır. Ayrıca Holden vd.(1979) döviz kuru ile ihracat arasında negatif bir ilişki olduğunu, Mariano vd.(2016) döviz kuru ile ithalat kısıtlamaları arasında pozitif bir ilişki olduğunuortaya koymuşlardır. Dolayısılla çalışmada çıkan sonuçlarla ile literatürde yapılan çalışmalarda çıkan sonuçlar benzerlik göstermektedir.

Döviz kurunun \%5 anlamlıık düzeyinde dış ticaret dengesinin Granger nedeni olduğu fakat dış ticaret dengesinin döviz kurunun Granger nedeni olmadığı görülmektedir. Başka bir ifadeyle, döviz kurundan dış ticaret dengesine doğru tek yönde ilişki bulunmuştur. İhracat ve ithalat arasındaki fark olarak tanımlanan dış ticaret dengesi ile ilgili olarak dış ticaret haddindeki ifade edildiği gibi ihracat ve ithalattaki değişimlerin döviz kuru üzerinde etkisinin olduğu söylenebilmektedir. Literatürde yapılan çalışmalar incelendiğinde şimşek(2004) ve Chowdhury(2012)'in yaptıkları çalışmalarda dış ticaret dengesinin uzun dönemde reel döviz kurunu etkilediği görülmektedir. Dolayısıyla çalışmada çıkan sonuçlarla ile literatürde yapılan çalışmalarda çıkan sonuçlar benzerlik göstermektedir.

Son olarak döviz kurunun \%10 anlamlılık düzeyinde petrol fiyatlarının Granger nedeni olduğu görülmektedir. Bununla birlikte petrol fiyatlarının da \%5 anlamlılık düzeyinde döviz kurunun Granger nedeni olduğu görülmektedir. Dolayısıyla döviz kuru ve petrol fiyatları arasında karşılıklı nedensellik olduğu söylenebilir. Literatürde yapılan çalışmalar incelendiğinde Khan(2014) yaptığı çalışmada petrol fiyatlarının 
döviz kurunu etkileyen en önemli faktörlerden biri olduğunu ve Mariano vd.(2016) ise yaptıkları çalışmada petrol fiyatları ile döviz kuru arasında negatif ilişki olduğu sonuçlarına ulaşmışlardır. Dolayısıyla çalışmada çıkan sonuçlarla ile literatürde yapılan çalışmalarda çıkan sonuçlar benzerlik göstermektedir.

\section{Şekil 2: Değişkenlerin Arasındaki Nedensellik İlişkisi}

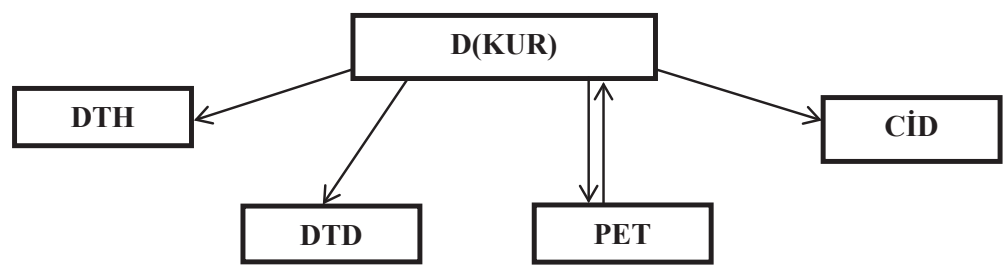

\section{Sonuç}

Hanehalkı, firma sahipleri ve ekonomi yöneticileri için son yıllarda ülkemizde üzerinde en çok konuşulan makroekonomik gösterge hiç kuşkusuz döviz kuru göstergesi olmuştur. Ülkede yaşayan hemen hemen herkesi ilgilendiren döviz kuru, hanehalkının tüketmek için aldığı üründen, üreticinin ürettiği ürünün maliyetine kadar ve ülkenin önemli makroekonomik göstergeleri etkilemesi açısından son derece önem arz etmektedir. Dolayısıyla söz konusu sebeplerden dolayı döviz kuru üzerinde etkili olan makroekonomik göstergelerin incelenmesi ve çıkan sonuçların ekonomi yöneticilerine yol göstermesi önemlidir.

Çalışmada Türkiye ekonomisinden 1988Q1-2019Q2 dönemini kapsayan veriler kullanımış olup, analiz kısmında döviz kurları ile seçilmiş makroekonomik göstergeler arasındaki etkileşim Granger nedensellik testi kullanılarak incelenmiştir. Veri setinde yer alan seçilmiş makroekonomik göstergeler literatürde yer alan çalışmalardan esinlenerek modele dâhil edilmiştir. Cari işlemler dengesi, dış ticaret dengesi, dış ticaret haddi ve petrol fiyatları olmak üzere dört değişkenin döviz kuru ile nedensellik ilişkisi bulunmuştur. Granger nedensellik analizi için gerekli varsayım olan durağanlığı test etmek için ADF birim kök testi kullanılmış ve serilerin durağan olduğu görülmüştür. Ardından Granger nedensellik testi için Schwarz bilgi kriteri kullanılarakoptimal gecikme uzunluğu belirlenmiş ve optimal gecikme uzunluğu 1 olarak bulunmuştur. Son olarak Granger nedensellik testi uygulanarak değişkenler arasında nedensellik ilişkisinin yönü belirlenmeye çalışılmıştır. 
Çalışmanın sonucunda döviz kuru ile cari işlemler dengesi, dış ticaret haddi, dış ticaret dengesin ve petrol fiyatları arasında nedensellik ilişkisi bulunmuştur. Başka bir ifadeyle, döviz kurundan cari işlemler dengesi, dış ticaret haddi, dış ticaret dengesine doğru tek yönlü, döviz kuru ile petrol fiyatları arasında ise karşııklı nedensellik ilişkisi bulunmuştur. Sonuç olarak çalışmada kullanılan değişkenlerin ve bulguların literatürde yapılan çalışmaların değişkenleri ve bulgularıyla benzerlik gösterdiği görülmektedir.

Bulgulara göre döviz kurlarında meydana gelen değişmelerin cari işlemler dengesi, dış ticaret haddi, dış ticaret dengesi ve petrol fiyatları üzerinde etkisinin olduğunu göstermektedir. Bu durum dış ticarette olumlu gelişmelerin yaşanması için döviz kurunun ne kadar önemli olduğunu ispatlamaktadır. Döviz kuru ve dış ticaret dengesinde yaşanan gelişmelerin de piyasalarda faiz oranı, para arzı, enflasyon oranı ve işsizlik oranı gibi diğer makro ve finansal göstergeleri de etkileyeceğinden dolayı döviz kurlarında aşıı dalgalanmaların önlenmesi ülke ekonomisi için oldukça önemlidir. Bununla birlikte Türkiye ekonomisinde döviz kurunun aşırı dalgalanmasını önlemek için tasarruf oranlarının artırıması, üretim ve ihracata dayalı bir ekonomik modelin istikrarlı bir şekilde uygulanması alınabilecek ekonomik politika önerileri arasında yer almaktadır.

Bu çalışma, Türkiye'de gelecekteki döviz kurları için önemli faktörlerin belirlenmesi ve tahmin edilmesinde önem taşıyacaktır. Dolayısılla hükümetin ve ekonomi yöneticilerinin yaklaşan değişikliklere hazırlıkı olmasına, gerçekçi ve doğru kararlar vermesine yardımcı olacaktır. 


\section{Kaynakça}

1. Abdoh, Wan Mohd Yaseer Mohd, Yusuf, Noor Hafizha Muhamad, Zulkifli, Shaliza Azreen Mohd, BULOT, Norhisam ve IBRAHIM, Nor Jamilah. (2016). Macroeconomic Factors That Influence Exchange Rate Fluctuation in ASEAN Countries. International Academic Research Journal of Social Science, 2(1): 89-94.

2. Arıcan, Erişah ve Tanınmış Yücememiş, Başak. (2015). Para Politikaları Işığında Türk Bankacılık Sektörü Genel Değerlendirmesi, İktisadi Araştırmalar Vakfı, 27: $1-12$.

3. Arize, Augustine C.,Osang, Thomas ve Slottje, J. Slottje. (2000). Exchange Rate Volatility and Foreign Trade: Evidence from thirteen LDCs," Journal of Business and Economics Statistics, 18(1): 10-17.

4. Candelon, Bertrand, Kool, Clemens, Raabe, Katharina veVan Veen, Tom. (2007). "Long-run Real Exchange Rate Determinants: Evidence From Eight New EU Member States, 1993-2003". Journal of Comparative Economics, 35(1): 87-107.

5. Cayen, Jean-Philippe. Coletti, Donald.Lalonde, Rene ve Maier, Philipp. (2010). What Drives Exchange Rates? New Evidence From a Panel of US Dollar Bilateral Exchange Rates. Bank of Canada Working Paper(2010-5).

6. Chowdhury, Khorshed. (2012). Modelling the Dynamics, Structural Breaks and the Determinants of the Real Exchange Rate of Australia. Journal of International Financial Markets, Institutions and Money, 22(2): 343-358.

7. Gujarati, Damodar N. (2003), Basic Econometrics, McGraw Hill, Singapure.

8. Gül, Ekrem. Ekinci, Aykut ve Özer, Mustafa, (2007). The Causal Relationship between Interest Rates and Exchange Rates in Turkey: 1984-2006. Journal of Economic, Management and Finance, 22(251): 21-31.

9. Granger, C.W.J. (1969) "Investigating Causal Relations By Econometric Models and Cross-Spectral Methods", Econometrica, 37(3):424-438.

10. Heller, H. Robert. (1978). "Determinants of Exchange Rate Practices". Journal of Money, Credit and Banking, 10(3): 308-321.

11. Holden, Paul. Holden, Merle ve Suss, Esther. (1979). The Determinants of 
Exchange RateFlexibility: An Empirical Investigation, The Review of Economics and Statistics, 61(3): 327-333.

12. Juhn, Grace ve Mauro, Paolo. (2002). "Long-Run Determinants of Exchange Rate Regimes A Simple Sensitivity Analysis". IMF Working Paper.No: 02/104.

13. Kaplan, Fatih ve Yapraklı, Sevda. (2014). Ekonomik Kırılganlık Endeksi Göstergelerinin Döviz Kuru Üzerindeki Etkileri: Kırılgan 12 Ülke Üzerine Panel Veri Analizi. Uluslararası Alanya Işletme Fakültesi Dergisi, 6 (3): 111-121.

14. Kartal, Mustafa Tevfik, Depren Kılıç, Serpil ve Depren, Özer. (2018). Türkiye'de Döviz Kurlarını Etkileyen Makroekonomik Göstergelerin Belirlenmesi: Mars Yöntemi İle Bir İnceleme. MANAS Sosyal Araştırmalar Dergisi, 7(1): 209-229.

15. Khan, Raja Sher Ali. (2014). Analysis If The Factors Affecting Exchange Rate Variability in Pakistan. IOSR Journal of Business and Management, 16(6): 115-121.

16. Kia, Amir. (2013). Determinants of The Real Exchange Rate in a Small Open Economy: Evidence From Canada. Journal of International Financial Markets, Institutions and Money, 23: 163-178.

17. Mariano, Christine Niziel Q.. Sablan, Vanessa F.. Sardon, Joshua Ray C. ve Paguta, Ronald. (2016). Investigation of the Factors Affecting Real Exchange Rate in the Philippines. Review of Integrative Business and Economics Research, 5(4): 171-202.

18. Mirchandani, Anita. (2013). Analysis of Macroeconomic Determinants of Exchange Rate Volatility in India. International Journal of Economics and Financial Issues, 3(1): 172-179.

19. Monica, S., ve Santhiyavalli, G. (2017). Determinants of Exchange Rate of Indian Rupee Against Us Dollar. International Journal of Commerce and Management Research, 3(1): 54-58.

20. Parveen, Shabana. Khan, Abdul Qayyum ve Ismail, Muhammad. (2012). Analysis of The Factors Affecting Exchange Rate Variability in Pakistan. Academic Research International, 2(3): 670-674.

21. Ramasamy, Ravindran ve Abar, Soroush Karimi. (2015). Influence of Macroeconomic Variables on Exchange Rates. Journal of Economics, Business \& 
Management, 3(2): 276-281.

22. Saeed, Ahmed. Awan, Rehmat Ullah. Sial, Maqbool H. ve Sher, Falak. (2012). An Econometric Analysis of Determinants of Exchange Rate in Pakistan. International Journal of Business and Social Science, 3(6): 184-196.

23. Semuel, Hatane ve Nurina, Stephanie. (2015). Analysis of the Effect of Inflation, Interest Rates, and Exchange Rates on Gross Domestic Product (GDP) in Indonesia. Proceedings of the International Conference on Global Business, Economics, Finance and Social Sciences, 1-13.

24. Şimşek, Muammer. (2004). Türkiye'de Reel Döviz Kurunu Belirleyen Uzun Dönemli Etkenler. Cumhuriyet Üniversitesi İktisadi ve İdari Bilimler Fakültesi Dergisi, 5(2): 1-24.

25. Şit, Mustafa ve Karadağ, Haydar. (2019). Döviz Kurunu Belirleyen Ekonomik Faktörler: Türkiye Ekonomisi İçin ARDL Sınır Testi Uygulaması.International Journal of Economic \& Administrative Studies, 23, 151-167.

26. Twarowska, Katarzyna ve KAKOL, Magdalena. (2014). Analysis of Factors Affectng Fluctuations in The Exchange Rate of Polish Zloty Against Euro. Managemenet, Knowledge and Learning, International Conference (25-27 June 2014 Portoroz, Slovenia) 889-898.

27. Urrutia, Jackie D. Olfindo, Merrill Lynch T. ve Tampis, Razzcelle. (2015). “Modellıng and Forecastıng The Exchange Rate Of The Phılıppınes: A Tıme Serıes Analysı". American Research Thoughts. 1(9): 1880-1937. 